\title{
Research Paper: Determinants of Authoritative Parenting Style in Iranian Mothers
}

Bita Bahrami $^{1}$, Behrooz Dolatshahi ${ }^{1 *}$, Abbas Pourshahbaz ${ }^{1}$, Parvaneh Mohammadkhani ${ }^{1}$

1. Department of Clinical Psychology, University of Social Welfare and Rehabilitation Sciences, Tehran, Iran.

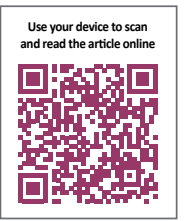

Citation: Bahrami B, Dolatshahi B, Pourshahbaz A, Mohammadkhani P. Determinants of Authoritative Parenting Style in Iranian Mothers. Iranian Rehabilitation Journal. 2017; 15(4):317-324. https://doi.org/10.29252/NRIP.IRJ.15.4.317

: https://doi.org/10.29252/NRIP.IRJ.15.4.317

Article info:

Received: 29 Feb. 2017

Accepted: 01 Jun. 2017
Keywords:

Parenting, Personality,

Temperament

\begin{abstract}
A B S T RACT
Objectives: The primary goal of this study was to identify the determinants of mother's authoritative parenting style upon the ecological model of parenting. There are some factors involved in this model such as a parent (i.e. developmental history, personality), and child characteristics (i.e. temperament and developmental issues) and environmental factors.

Methods: The statistic population of this study includes mothers in Tehran having preschool children between 4-6 years old. By convenient sampling, eight kindergarten schools were selected, and mothers completed the questionnaires. The sample consisted of 157 mothers who had the authoritative parenting style based on the score of Baumrind's parenting style questionnaire. The participants completed the questionnaires and data was analyzed with regression analysis.

Results: The parent's neuroticism $(\mathrm{r}=-0.253, \mathrm{P}<0.01)$, social support $(\mathrm{r}=-0.200, \mathrm{P}<0.05)$ and some temperamental characteristics of child i.e. excitability $(\mathrm{r}=-0.526, \mathrm{P}<0.01)$ and activity $(\mathrm{r}=-0.163, \mathrm{P}<0.05)$ were significant variables in prediction of authoritative parenting style

Discussion: This study enhances our understanding of the primary determinants of authoritative parenting style in Iranian mothers. The authoritative parenting style is a function of interactional mother and child characteristic and contextual components. These parents had a low score on neuroticism. Therefore, they had emotional stability and could manage their impulse and negative emotions about child maltreatment. Also, their children had low scores in excitability and a high score in sociability. Additionally, the authoritative mothers had weak social support. One explanation for this result is that mothers are the autonomy people and stand on their own rules and had little need to others.
\end{abstract}

\section{Introduction}

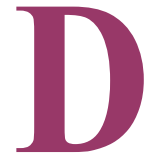

iana Baumrind is a leader in the explanation of parenting styles. Baumrind [1] reviewed the literature on conventional parenting subjects and presented the permissive, authoritative, and authoritarian parenting styles. Permissive parents displayed a no punitive attitude of acceptance of their child's behaviors, made few demands on the child. Authoritarian parents acted on the opposite end of 
the spectrum of parenting styles. Authoritarian parents valued obedience and attempted to control their children with punitive ways. These parents set standards and expectations for their child, but also affirmed the child's individuality and encouraged growth and autonomy, and they presented the affection to the child.

Many studies in the field of parenting style determinants are using of Belsky's ecological model [2]. In this theory, there are some factors such as a parent (i.e. developmental history, personality), and child characteristics (i.e. temperament and developmental issues), and environmental factors [3]. A parent's personality will determine his parenting style. Baumrind [1] found that parents who were controlling, demanding, and loving had self-controlled and assertive children. Furthermore, parent's developmental history plays an essential role in the parenting manners. Prior study has shown that parents' representations of their relationships with their parents affect future parenting style and their children's later development [4].

The second domain contained within Belsky's model is child characteristics. Temperament is coded within a child's genetic framework. Therefore, the genetic structure of a child's personality determines how his behaviors will be expressed. In general, children with easy temperaments have easier to read and predict behaviors than children with difficult temperaments. The third domain in Belsky's model is contextual sources of support or stress. This factor examines the critical sources of potential stress or support: the marriage relationship, the parent's job, and social network. Social support means that one is cared for and belonged to a system of communication. Studies have shown that a more supported mother responds less restrictive to her child $[5,6]$. Also, there is evidence that mothers who are dissatisfied with their employment status have children whose development is further from optimal than those whose mothers are more satisfied with their job situation $[3,7]$.

Finally, literature showed that marital satisfaction has an important effect on parenting behaviors in mothers and fathers. This finding has seen in many countries and children of various age groups [8]. While each of these categories-child characteristics, parent personality, and contextual sources of support or stressinfluences parenting, examining one single component neglects the other crucial areas. Also, there are various studies about the parenting style's effect on child development, but the critical question for some studies like the present study was that "what are the determinants of parenting?"

It is reported that many factors predicted parenting style. However, the majority of the studies investigated the effect of one or two factor on parenting style. Therefore present studies provide little information about which dimension of the whole elements impacted the parenting style [6]. Also, the parenting style and its determinants are different in every culture. For example, the dominant parenting style in the Western world is authoritative and in Arab is authoritarian. Since there is a cultural difference in parenting styles, the need to study parenting style of Iranian mothers is necessary [6]. The clarification of the primary determinants in Iranian mothers helps the child and family professionals to develop an intervention program that is specific to Iranian culture.

The present study explored the personality and attachment style in parent's domain, social support, marital satisfaction, work-family interface in contextual domain, and temperament in child's domain as determinants of authoritative parenting. According to the explanations above, the central question of this study was that "what is the determinant of authoritative parenting in Iranian mothers?"

\section{Methods}

The statistic community of this study was the mothers in Tehran who have preschool children between 4-6 years old. By convenient sampling, eight kindergarten schools were selected and the justification of welfare organization for this study given to the principals of the kindergartens. Then, two questioners (students of psychology) were trained to administer the questionnaires in the kindergartens. The researchers explained the purpose, significant and voluntary participation in the study for each participant. Also, the confidentiality of their responses was informed.

The sample consisted of 272 mothers with preschool children (age range 4-6), who were participating in this study and had the authoritative parenting style based on the score of Baumrind's parenting style questionnaire.

The sample size was $271.9 \approx 272$ (Variance $=0.5$, confidence interval: $\% 0.95, \mathrm{Z}_{0.05}=1.649$, and $\mathrm{d}=0.05$ ). After the administration of questionnaires, the result of parenting styles analysis showed that 157 mothers had an authoritative parenting style. The whole of the sample worked outside of the home. Mean years of age for 
mothers was $35.2915, \mathrm{SD}=4.46532$, and for children was $5.336, \mathrm{SD}=0.86598$.

\section{Parenting Style Questionnaire}

Parenting Style Questionnaire [9] comprises 30 items (10 items per domain): permissive, authoritative, and authoritarian parenting styles were measured by this questionnaire. The reliability of the test was calculated by Cronbach's alpha. The Cronbach's alpha of permissive, authoritarian, and authoritative style in order were 0.855 , $0.921,0.962$.

\section{NEO Five-Factor Inventory (NEO-FFI)}

The NEO Five-Factor Inventory (NEO-FFI) [10] comprises 60 items (12 items per domain) was administered. This scale assesses the extraversion, agreeableness, conscientiousness, neuroticism, and openness to experience. For the NEO FFI (the 60 item domain only version) the internal consistencies accounted in the manual were: $\mathrm{N}=0.79, \mathrm{E}=0.79, \mathrm{O}=0.80, \mathrm{~A}=0.75, \mathrm{C}=0.83$ [3]. The reliability of the test was calculated by Cronbach's alpha. The agreeableness, neuroticism, conscientiousness, openness to experience and extraversion had acceptable Cronbach's alpha coefficient. These coefficients in order were $0.606,0.67,0.85,0.964$, and 0.557 .

\section{Hazan and Shaver's Attachment Style Questionnaire}

Participants received 15 statements ( 5 items per attachment style) [10]. This 15-item scale was highly reliable in studies with Israeli samples and has high validity. The Cronbach's alpha of secure, anxious, and avoidant attachment in order were $0.783,0.765,0.862$.

\section{Malhotra's Temperament Schedule (MTS)}

Malhotra's Temperament Schedule (MTS) [9] assesses temperament of children and measures the temperament traits identified by Thomas, Chess, and Birch in Hindi. Activity, excitability, regularity, sociability, and distractibility were measured by this scale. It has accepted reliability and validity. The test-retest reliability of this measurement is 0.83 to 0.94 . The Cronbach's alpha of activity, the focus of attention, excitability, sociability, and regularity in order were $0.782,0.574,0.831,0.702,0.759$.

\section{Marital Satisfaction Scale}

Marital satisfaction scale [11] is a five-point Likert scale consisting of 47 questions and has been used in different studies as a valid instrument to measure marital satisfaction. Psychometric properties of the scale were cheeked by Fowers and Olson [12]. This questionnaire is related to the changes happening during human life and is sensitive to the changes occurring in the family. The Cronbach's alpha of test in this study was 0.876 .

\section{Work-Family Conflict Scale}

Work-Family Conflict Scale [13] comprises of 9 item that measures family interference with work. Three items each measure different aspects of family interference with work, i.e. strain-based, time-based, and behaviorbased work-family conflicts. Higher numbers of scales represent greater conflict. This scale has high reliability $(\alpha=0.89)$, and high construct and content validities [13]. The Cronbach's alpha of test in this study was 0.837 .

Gross and John's Emotion Regulation Questionnaire

Gross and John's emotion regulation questionnaire [14] is a 10-item questionnaire designed to measure participants' tendency to regulate their emotions. Participants answer each item on a 7-point Likert-type scale ranging from 1 (strongly disagree) to 7 (strongly agree). Test-retest reliability was 0.69 . The Cronbach's alpha of test in this study was 0.809 .

\section{Social Support Appraisals Scale (SS-A)}

The Social Support Appraisals Scale (SS-A) is a 23item instrument based on Cobb's [10, 12] definition of social support and designed to tap the extent to which the person believes that he or she is loved by, and involved with family, friends, and others. The Cronbach's alpha of test in this study was 0.701 .

\section{Results}

The descriptive statistics for all scales (personality and attachment style, and authoritative parenting style in parent's domain, social support, marital satisfaction, workfamily interface in contextual domain, and temperament in child's domain) were derived by calculating the mean and standard deviation (Table 1).

Bivariate correlations between the authoritative parenting style and the mother's personality and attachment style, marital relationship, work-family interface, social support, and the infant's temperament were examined. There is a significant negative correlation between authoritative parenting and neuroticism $(\mathrm{r}=-0.253, \mathrm{P}<0.01)$, social support $(\mathrm{r}=-0.200, \mathrm{P}<0.05)$, excitability $(\mathrm{r}=-0.526$, $\mathrm{P}<0.01)$, activity $(\mathrm{r}=-0.163, \mathrm{P}<0.05)$ and a significant 
Table 1. Descriptive statistics for the authoritative parenting style and the mother's personality and attachment style, marital relationship, work-family interface, social support and the infant's temperament

\begin{tabular}{|c|c|c|c|}
\hline Variables & Subscales & Mean & SD \\
\hline Parenting style & 1. Authoritative & 29.9298 & 4.43499 \\
\hline \multirow{3}{*}{ Attachment style } & 2. Avoidance attachment & 7.3303 & 3.64064 \\
\hline & 3. Secure attachment & 17.9982 & 1.91630 \\
\hline & 4. Anxious attachment & 9.0059 & 3.32109 \\
\hline \multirow{5}{*}{ Personality } & 5. Neuroticism & 9.7402 & 4.51343 \\
\hline & 6. Extraversion & 25.2555 & 4.04199 \\
\hline & 7. Openness to experience & 23.2929 & 3.82779 \\
\hline & 8. Agreeableness & 22.9558 & 4.18963 \\
\hline & 9. Conscientiousness & 32.7512 & 5.67970 \\
\hline Social support & 10. Social support & 16.2870 & 2.26131 \\
\hline Family-work conflict & 11. Family-work conflict & 48.3620 & 7.22209 \\
\hline \multirow[t]{3}{*}{ Marital satisfaction } & 12. Marital satisfaction & 124.6853 & 16.69371 \\
\hline & 13. Sociability & 50.3582 & 7.02483 \\
\hline & 14. Excitability & 24.8431 & 5.26429 \\
\hline \multirow[t]{3}{*}{ Child's temperament } & 15. Activity & 32.9600 & 7.93794 \\
\hline & 16. Focus of attention & 15.5551 & 3.48167 \\
\hline & 17. Regularity & 17.4376 & 4.92500 \\
\hline
\end{tabular}

Mranlan Rkhabullution Journa

positive correlation between authoritative parenting style and sociability $(\mathrm{r}=0.474, \mathrm{P}<0.01)$ (Table 2$)$.

The unique contributions of personality, attachment style, social support, marital satisfaction, work-family interface and temperament in the prediction of authoritative parenting style was tested by regression. For this purpose, the variables that had a significant correlation with the authoritative parenting style in a prior step (i.e. neuroticism, social support, excitability, activity, and sociability) were entered into regression analysis. Results indicated that all of the variables were significant $(\mathrm{P}<0.05)$ in the prediction of authoritative parenting except the activity. The Beta coefficient of neuroticism, social support, sociability, excitability, and activity were $-0.154,-0.163,0.280,-0.327,-0.085$, respectively. The $\mathrm{R}^{2}$ was 0.39 . The regression analysis results presented in Table 3 . The regression equation for authoritative parenting style is presented below:

$$
Y=a+b x
$$

Authoritative parenting style $=36.124-0.151\left(X_{1}\right)$ $0.32\left(X_{2}\right)-0.275\left(X_{3}\right)+0.177\left(X_{4}\right)$

Authoritative parenting style $=36.124-0.151$ (Neuroticism)-0.32(social support)-0.275(Sociability)+ 0.177 (Excitability)

\section{Discussion}

In the present study, the determinants of authoritative parenting style of Iranian mothers based on Belsky's ecological model were investigated. The results of the present study are supported by the Belsky's theory that multiple factors including parental, contextual, and child factors influence the authoritative parenting style.

The current study showed the significant negative correlation between authoritative parenting style and neu- 
Table 2. Intercorrelation of study variables (the authoritative parenting style and the mother's personality and attachment style, marital relationship, work-family interface, social support and the infant's temperament)

\begin{tabular}{|c|c|c|c|c|c|c|c|c|}
\hline \multicolumn{2}{|c|}{ Variables } & \multirow{2}{*}{$\begin{array}{l}1 \\
1\end{array}$} & \multirow{2}{*}{$\frac{2}{-0.024}$} & \multirow{2}{*}{$\begin{array}{c}3 \\
0.156\end{array}$} & \multirow{2}{*}{$\begin{array}{c}4 \\
-0.091\end{array}$} & \multirow{2}{*}{$\begin{array}{c}\mathbf{5} \\
-0.253^{* *}\end{array}$} & \multirow{2}{*}{$\begin{array}{c}6 \\
0.125\end{array}$} & \multirow{2}{*}{$\begin{array}{c}7 \\
0.032\end{array}$} \\
\hline Parenting style & 1. Authoritative & & & & & & & \\
\hline \multirow{3}{*}{ Attachment style } & 2. Avoidance attachment & -0.024 & 1 & 0.066 & -0.083 & 0.088 & 0.073 & -0.069 \\
\hline & 3. Secure attachment & 0.156 & 0.066 & 1 & 0.006 & $-0.250^{* *}$ & 0.057 & 0.029 \\
\hline & 4. Anxious attachment & -0.091 & -0.083 & 0.006 & 1 & 0.081 & $-0.189^{*}$ & 0.011 \\
\hline \multirow{5}{*}{ Personality } & 5. Neuroticism & $-0.253^{* *}$ & 0.088 & $0.250^{* *}$ & 0.081 & 1 & $-0.208^{* *}$ & -0.115 \\
\hline & 6. Extraversion & 0.125 & 0.073 & 0.057 & $-0.189 *$ & $-0.208 * *$ & 1 & 0.114 \\
\hline & 7. Openness to experience & 0.032 & -0.069 & 0.029 & 0.011 & -0.115 & 0.114 & 1 \\
\hline & 8. Agreeableness & 0.056 & 0.040 & -0.014 & -0.067 & 0.118 & $0.184^{*}$ & $0.249 * *$ \\
\hline & 9. Conscientiousness & 0.043 & -0.034 & 0.021 & -0.056 & $-0.314 * *$ & -0.065 & 0.039 \\
\hline Social support & 10. Social support & $-0.200^{*}$ & 0.013 & $0.230^{* *}$ & -0.059 & -0.097 & 0.078 & 0.006 \\
\hline Family-work conflict & 11. Family-work conflict & -0.059 & $-0.170^{*}$ & -0.030 & 0.106 & 0.039 & -0.116 & -0.069 \\
\hline \multirow[t]{3}{*}{ Marital satisfaction } & 12. Marital satisfaction & -0.137 & -0.034 & -0.061 & 0.038 & -0.024 & 0.085 & 0.015 \\
\hline & 13. Sociability & $0.474^{* *}$ & -0.069 & 0.093 & $-0.164 *$ & $-0.170^{*}$ & 0.024 & -0.048 \\
\hline & 14. Excitability & $-0.526 * *$ & 0.067 & -0.011 & 0.146 & $0.203^{*}$ & -0.088 & 0.083 \\
\hline \multirow[t]{4}{*}{ Child's temperament } & 15. Activity & $-0.163^{*}$ & 0.037 & 0.065 & 0.041 & 0.010 & $0.169 *$ & 0.150 \\
\hline & 16. Focus of attention & 0.004 & 0.090 & -0.080 & $-0.183^{*}$ & -0.047 & 0.066 & 0.032 \\
\hline & 17. Regularity & -0.124 & 0.047 & -0.003 & -0.002 & 0.131 & -0.071 & 0.060 \\
\hline & & 8 & 9 & & & 11 & 12 & 13 \\
\hline \multirow[t]{2}{*}{ Parenting style } & 1. Authoritative & 0.056 & 0.043 & & $00^{*}$ & -0.059 & -0.137 & $0.474 * *$ \\
\hline & 2. Avoidance attachment & 0.040 & -0.034 & & & $-0.170^{*}$ & -0.034 & -0.069 \\
\hline \multirow[t]{2}{*}{ Attachment style } & 3. Secure attachment & -0.014 & 0.021 & & $0^{* *}$ & -0.030 & -0.061 & 0.093 \\
\hline & 4. Anxious attachment & -0.067 & -0.056 & & & 0.106 & 0.038 & $-0.164 *$ \\
\hline \multirow{5}{*}{ Personality } & 5. Neuroticism & 0.118 & $-0.314^{* *}$ & & 97 & 0.039 & -0.024 & $-0.170 *$ \\
\hline & 6. Extraversion & $0.184^{*}$ & -0.065 & & 78 & -0.116 & 0.085 & 0.024 \\
\hline & 7. Openness to experience & $0.249^{* *}$ & 0.039 & & 06 & -0.069 & 0.015 & -0.048 \\
\hline & 8. Agreeableness & 1 & $-0.181^{*}$ & & 08 & -0.061 & -0.109 & -0.088 \\
\hline & 9. Conscientiousness & $-0.181^{*}$ & 1 & & 73 & -0.046 & -0.043 & 0.113 \\
\hline Social support & 10. Social support & 0.008 & 0.073 & & & -0.139 & $-0.167^{*}$ & 0.019 \\
\hline Family-work conflict & 11. Family-work conflict & -0.061 & -0.046 & & & 1 & $0.317^{* *}$ & -0.076 \\
\hline \multirow[t]{3}{*}{ Marital satisfaction } & 12. Marital satisfaction & -0.109 & -0.043 & & $67^{*}$ & $0.317^{* *}$ & 1 & -0.042 \\
\hline & 13. Sociability & -0.088 & 0.113 & & & -0.076 & -0.042 & 1 \\
\hline & 14. Excitability & -0.033 & -0.132 & & & 0.072 & 0.057 & $-0.470 * *$ \\
\hline \multirow[t]{3}{*}{ Child's temperament } & 15. Activity & 0.052 & -0.042 & & & -0.054 & $0.183^{*}$ & $-0.205^{*}$ \\
\hline & 16. Focus of attention & -0.021 & 0.124 & & $95^{*}$ & $-0.161^{*}$ & 0.111 & -0.013 \\
\hline & 17. Regularity & 0.005 & -0.051 & & 64 & 0.142 & 0.067 & -0.101 \\
\hline
\end{tabular}




\begin{tabular}{|c|c|c|c|c|c|}
\hline \multicolumn{2}{|c|}{ Variables } & \multirow{2}{*}{$\begin{array}{c}14 \\
-0.526^{* *}\end{array}$} & \multirow{2}{*}{$\begin{array}{c}15 \\
-0.163^{*}\end{array}$} & \multirow{2}{*}{$\begin{array}{c}16 \\
0.004\end{array}$} & \multirow{2}{*}{$\begin{array}{c}17 \\
-0.124\end{array}$} \\
\hline Parenting style & 1. Authoritative & & & & \\
\hline \multirow{3}{*}{ Attachment style } & 2. Avoidance attachment & 0.067 & 0.037 & 0.090 & 0.047 \\
\hline & 3. Secure attachment & -0.011 & 0.065 & -0.080 & -0.003 \\
\hline & 4. Anxious attachment & 0.146 & 0.041 & $-0.183^{*}$ & -0.002 \\
\hline \multirow{5}{*}{ Personality } & 5. Neuroticism & $0.203^{*}$ & 0.010 & -0.047 & 0.131 \\
\hline & 6. Extraversion & -0.088 & $0.169 *$ & 0.066 & -0.071 \\
\hline & 7. Openness to experience & 0.083 & 0.150 & 0.032 & 0.060 \\
\hline & 8. Agreeableness & -0.033 & 0.052 & -0.021 & 0.005 \\
\hline & 9. Conscientiousness & -0.132 & -0.042 & 0.124 & -0.051 \\
\hline Social support & 10. Social support & $0.183^{*}$ & -0.031 & $-0.195^{*}$ & -0.064 \\
\hline Family-work conflict & 11. Family-work conflict & 0.072 & -0.054 & $-0.161^{*}$ & 0.142 \\
\hline \multirow[t]{3}{*}{ Marital satisfaction } & 12. Marital satisfaction & 0.057 & $0.183^{*}$ & 0.111 & 0.067 \\
\hline & 13. Sociability & $-0.470 * *$ & $-0.205^{*}$ & -0.013 & -0.101 \\
\hline & 14. Excitability & 1 & 0.072 & $-0.173^{*}$ & 0.043 \\
\hline \multirow[t]{3}{*}{ Child's temperament } & 15. Activity & 0.072 & 1 & $0.308^{* *}$ & -0.014 \\
\hline & 16. Focus of attention & $-0.173^{*}$ & $0.308^{* *}$ & 1 & -0.015 \\
\hline & 17. Regularity & 0.043 & -0.014 & -0.015 & 1 \\
\hline
\end{tabular}

roticism. The role of neuroticism in parenting practices was emphasized in the literature [15]. Individuals with high scores in neuroticism tend to be anxious, irritable, and emotionally unstable. These traits interfere with positive parenting because these parents are not able to focus on children's requirement.

Maternal parenting that is high in authoritarian and permissive had high scores in neuroticism. The result showed that the authoritative parents have low scores on this characteristic, then they can have a reasonable control over their children.
Another finding of the present study showed that there was a significant negative correlation between authoritative parenting and social support. Pascoe et al. [16] found that social network communication and supportiveness correlated positively with the psychical organization of the child's world, and with mothers' avoidance of punishment, nag, and restriction, which is inconsistent with the present study. Belsky [3,9] viewed the marital relationship as one of the potential sources of support in the parenting process. However, these studies expanded the model to include other sources of social support such as family members, co-workers, and friends.

Table 3. Regression analysis for prediction of authoritative parenting style

\begin{tabular}{cccccc}
\hline & B & $\mathbf{R}^{2}$ & Beta. & T. & Sig. \\
\hline Constant & 36.124 & & 8.846 & 0.000 \\
Neuroticism $\left(X_{1}\right)$ & -0.151 & & -0.154 & -2.342 & 0.020 \\
social support $\left(X_{2}\right)$ & -0.32 & 0.39 & -0.163 & -2.483 & 0.014 \\
Sociability $\left(X_{3}\right)$ & -0.275 & & 0.280 & 3.779 & 0.000 \\
Excitability $\left(X_{4}\right)$ & 0.177 & -0.327 & -4.367 & 0.000 \\
Activity $\left(X_{5}\right)$ & -0.048 & -0.085 & -1.312 & 0.192 \\
\hline
\end{tabular}


Finally, finding showed that the sociability of a child could positively predict the authoritative parenting, and the excitability of a child could predict it negatively. The positive association between sensitive, responsive maternal parenting style, and children's early socioemotional functioning is well documented [4, 17, 18]. Jenkins, Rasbash, and O'Connor [14, 19] found that children with more difficult temperaments (described as aggressive, negative, or irritable) were received more negative parental behaviors than their siblings who were described as having a more manageable temperament. Clark, Kochanska, and Ready [20, 21] studied a sample that consisted of 112 mother-child dyads, assessed at the age of 8 to 10 months old and then at 13-15 months old. They have examined children's negative emotionality (in both laboratory and naturalistic settings), mother's use of power, mother's personality, and two measures of maternal responsiveness. Overall the study found that children's negative emotionality evoked a higher level of "power-assertive style" (a less responsive, more authoritarian) of parenting. This study continues to support the hypothesis that a child's temperament solicits specific types of parental treatment and attitudes.

The results of the present study showed that the authoritative parents had a low score on neuroticism. Therefore, they had emotional stability and could manage their impulse and negative emotions about child maltreatment. Additionally, their children had low scores in excitability and a high score in sociability. According to theories the temperament of the child could elicit the specific behaviors in parents [7]. The high sociability and low excitability in the children affected on parenting style and provoked the authoritative parenting behaviors. Furthermore, the authoritative mothers had weak social support. One explanation for this result is that these mothers are the autonomy people and stand on their own rules and had a little needs to others [10].

This study has few limitations: 1 . This study was performed on mothers and a similar study on fathers is required; 2. Similar to other studies in this area we solely used self-report measures, further studies are required which should include information gathered via multiple methods from multiple sources, for example an observational method is offered; 3 . Present study investigated the determinants of authoritative parenting, and other parenting style's determinants (for example, permissive and authoritarian style) need to be studied; and 4. The convenient sampling, then the random sampling for the validation of result's generalization is necessary.

\section{Conclusion}

Despite these limitations, the result of this study helps us to know the primary determinants of authoritative parenting style in Iranian mothers. The authoritative parenting style is a function of mother and child characteristic and contextual components.

\section{Acknowledgments}

We express our appreciation to the parents and children who participated in the study and to the principals of the kindergartens and many research assistants who contributed to this study. Also, the present study is a part of a $\mathrm{PhD}$ dissertation that was accomplished in Department of Clinical Psychology, University of Social Welfare and Rehabilitation Sciences in Tehran, Iran.

\section{Conflict of Interest}

The authors declared no conflicts of interest.

\section{References}

[1] Allen JG, Fonagy P. The handbook of mentalization-based treatment. Hoboken, New Jersey: John Wiley \& Sons; 2006.

[2] Atella LD, DiPietro JA, Smith BA, St James-Roberts I. More than meets the eye: Parental and infant contributors to maternal and paternal reports of early infant difficultness. Parenting: Science and Practice. 2003; 3(4):265-84. doi: 10.1207/ s15327922par0304_1

[3] Van Bakel HJ, Riksen-Walraven JM. Parenting and development of one-year-olds: links with parental, contextual, and child characteristics. Child Development. 2002; 73(1):256-73. doi: 10.1111/1467-8624.00404

[4] Blandon AY, Calkins SD, Keane SP, O'brien M. Contributions of child's physiology and maternal behavior to children's trajectories of temperamental reactivity. Developmental Psychology. 2010; 46(5):1089-1102. doi: 10.1037/a0020678

[5] Belsky J. The determinants of parenting: A process model. Child Development. 1984; 55(1):83-96. doi: 10.2307/1129836

[6] Carpenter JL, Mendez J. Adaptive and challenged parenting among African American mothers: Parenting profiles relate to head start children's aggression and hyperactivity. Early Education \& Development. 2013; 24(2):233-52. doi: 10.1080/10409289.2013.749762

[7] Chang H, Olson SL, Sameroff AJ, Sexton HR. Child effortful control as a mediator of parenting practices on externalizing behavior: Evidence for a sex-differentiated pathway across the transition from preschool to school. Journal of Abnormal Child Psychology. 2010; 39(1):71-81. doi: 10.1007/s10802-0109437-7 
[8] Flouri E. Fathering and child outcomes. Hoboken, New Jersey: John Wiley \& Sons; 2005.

[9] Kiff CJ, Lengua LJ, Zalewski M. Nature and nurturing: Parenting in the context of child temperament. Clinical Child and Family Psychology Review. 2011; 14(3):251-301. doi: 10.1007/ s10567-011-0093-4

[10] Madigan S, Atkinson L, Laurin K, Benoit D. Attachment and internalizing behavior in early childhood: A meta-analysis. Developmental Psychology. 2013; 49(4):672-89. doi: $10.1037 / \mathrm{a} 0028793$

[11] Krishnakumar A, Buehler C. Interparental conflict and parenting behaviors: A meta-analytic review. Family Relations. 2000; 49(1):25-44. doi: 10.1111/j.1741-3729.2000.00025.x

[12] Fowers BJ, Olson DH. Enrich Marital Inventory: A discriminant validity and cross-validation assessment. Journal of Marital and Family Therapy. 1989; 15(1):65-79. doi: 10.1111/ j.1752-0606.1989.tb00777.x

[13] Rehman RR, Waheed A. Work-family conflict and organizational commitment: Study of faculty members in Pakistani universities. Pakistan Journal of Social and Clinical Psychology. 2012; 10(1):23-6.

[14] Gross JJ, John OP. Individual differences in two emotion regulation processes: Implications for affect, relationships, and well-being. Journal of Personality and Social Psychology. 2003; 85(2):348-62. doi: 10.1037/0022-3514.85.2.348

[15] Parent J, Forehand R, Merchant MJ, Edwards MC, Conners-Burrow NA, Long N, et al. The relation of harsh and permissive discipline with child disruptive behaviors: Does child gender make a difference in an at-risk sample? Journal of Family Violence. 2011; 26(7):527-33. doi: 10.1007/s10896011-9388-y

[16] Woolfson L, Grant E. Authoritative parenting and parental stress in parents of pre-school and older children with developmental disabilities. Child: Care, Health and Development. 2006; 32(2):177-84. doi: 10.1111/j.1365-2214.2006.00603.x

[17] Luster T, Okagaki L. Parenting: An ecological perspective. Abingdon: Routledge; 2006.

[18] Grusec JE, Hastings PD. Handbook of socialization: Theory and research. New York: Guilford Publications; 2008.

[19] Jenkins JM, Rasbash J, O'connor TG. The role of the shared family context in differential parenting. Developmental Psychology. 2003; 39(1):99-113. doi: 10.1037/0012-1649.39.1.99

[20] Bates JE, Pettit GS. Temperament, parenting, and socialization. In: Grusec JE, Hastings PD, editor. Handbook of Socialization: Theory and Research. New York: Guilford Press; 2007.

[21] Clark LA, Kochanska G, Ready R. Mothers' personality and its interaction with child temperament as predictors of parenting behavior. Journal of Personality and Social Psychology. 2000; 79(2):274-85. doi: 10.1037//0022-3514.79.2.274 